\title{
EDITORIAL
}

\section{Establishing exposure science as a distinct scientific discipline}

Journal of Exposure Science and Environmental Epidemiology (2012)

22, 317-319; doi:10.1038/jes.2012.5

\section{BACKGROUND}

As readers of this journal, we are likely in agreement that "Exposure science is the bedrock for protection of public health.", and despite some differing opinions as to what the exact definition of "exposure science" should be, a general consensus states that it "... studies human contact with chemical, physical, or biological agents occurring in their environments, and advances knowledge of the mechanisms and dynamics of events either causing or preventing adverse health outcomes." ${ }^{2,3}$

We have probably also observed that, in the greater scheme of scientific professions, those who practice exposure science are erstwhile chemists, biologists, physicists, toxicologists, epidemiologists, mathematicians, computer scientists, statisticians, environmental engineers, and medical/public health doctors; few, if any, of us are formally trained "exposure scientists". Furthermore, exposure science tends to be considered a part of the other public health disciplines; the toxicologists, statisticians, and epidemiologists treat exposure as a subset of their disciplines, and often express concern about the lack of sufficient exposure information. In this article, we hope to promote exposure science as a distinct and recognizable scientific discipline.

The question is, how can we improve the perception, practice, and value of exposure science among the more established medical and public health disciplines?

The first step would be to develop a distinct scientific discipline; although this is a difficult and long-term effort, it can indeed be accomplished. Consider the history of toxicology from antiquity and over the past 50 years. Toxicology traces its roots back to Paracelsus (Phillippus Aureolus, 1493-1541 AD) who is credited with the dose response concept " ... the dose makes the poison." In modern times, toxicology split away from pharmacology and the medical professions; toxicologists established their first journal, Toxicology and Applied Pharmacology, in 1958, and officially established the Society of Toxicology in 1961. Today, there are 109 US University programs offering Doctorate degrees in Toxicology (http://www.gradschools.com) and there are currently at least 37 scientific journals with "Toxicology" in the title (extracted from: http://apps.isiknowledge.com).

Similarly, exposure science also has historic roots; the earliest observations were adverse health effects linked to occupational exposures in lead miners appearing in Egyptian scrolls. The bestknown historical example of a direct exposure to adverse health outcome is probably the description in 1808 by Sir Percivall Pott in London England, who observed that prolonged exposure to flue dusts resulted in "chimney sweeper's cancer" localized in the scrotum. Despite a series of anecdotal successes, the historical record of exposure science has always been intertwined with the other medical sciences until recently, when the International Society of Exposure Assessment (ISEA) was founded in 1989 and the Journal of Exposure Analysis and Environmental Epidemiology (JEAEE) was established in 1991 (the words "analysis" and "assessment" were replaced with "science" in 2006 and 2008, and became ISES and JESEE, respectively). In parallel, the British Occupational Hygiene Society has hosted six specialty conferences on the "Science of Exposure Assessment" since 1988.

To date, we are aware of only three US exposure assessment/ science specialty programs offering Doctoral degrees: University of Medicine and Dentistry of NJ with Rutgers University, NJ; University of California, Irvine, CA; Harvard University, MA. A number of other major schools of public health offer exposure assessment as a sub-specialty within broader degree programs. Of particular note is the emphasis by the National Institute for Occupational Safety and Health ${ }^{4}$ on training through its grants to Education and Research Centers (http://niosh-erc.org/) and Training Program Grants (http://www.cdc.gov/niosh/oep/trngrnt.html). Exposure science is an important component of the degree and research programs offered under these umbrellas.

Toxicology seems to have a 28-year head start on exposure science as a separate entity. Although employment opportunities for exposure scientists abound in Government Agencies, Research Institutes, and in the broader public health arena, the main contrast appears to be in the direct engagement of the academic community. Today, it is well understood what a $\mathrm{PhD}$ Toxicologist or Epidemiologist is; we should strive for the day that the PhD Exposure Scientist joins that list in the public's awareness.

\section{A PRAGMATIC PATH FORWARD}

From a logical perspective, there are certain common attributes among the established scientific disciplines:

(1) Recognizable identifier: Chemist, Biologist, Physicist, Epidemiologist, Toxicologist and so on.

(2) Identified job market: Academia, Industry, and Government.

(3) Education credentials: University Degree and/or Certification availability; PhD, MD, DPH, MPH, MS, BS, DABT, PE, CPA and so on.

(4) Professional peer group: International Associations, Journals, Scientific Meetings.

(5) Replacement stream: Continual development and recruitment of new talent updated with new technologies and concepts.

Our current broad identifier typically involves the word "environmental" (i.e. environmental scientist, environmental engineer, environmental toxicologist); we would hope to establish "Exposure Scientist" as our recognizable identifier. As mentioned above, we have made a good start with respect to identifying the job market and establishing a professional peer group (ISES). Where we need increased effort is in developing distinct educational credentials and a steady stream of highly motivated and trained practitioners of the art.

There are two basic components of the strategy to further the emergence of exposure science as a distinct scientific discipline: Awareness, which reflects the public relations or marketing aspects of attracting people to the science and Availability, which reflects the actual procedures for becoming a member of the group. These two pragmatic issues are discussed separately below.

\section{Awareness}

If we want to attract the best and brightest to exposure science, they need to become aware that such an option exists. From 
classical marketing, there are two basic competition and sales concepts that we could exploit. They are based on the psychology of consumer choice: Awareness set and Consideration set.

Awareness set: This concept exploits the basic philosophy that consumers cannot buy/use something that they are not aware of. The marketing solution is positioning or awareness advertisement to the susceptible population. It generally does not make comparisons or specific claims, but only inserts an entry into the consumer mindset as a possible choice.

Consideration set: This concept embraces the basic philosophy that a consumer creates an internal subset of the Awareness set called the Consideration set that incorporates perceptions about his/her needs and the relative value of the various entries in the Awareness set. The consumer then chooses only from the Consideration set, regardless of his/her awareness of broader possibilities. The marketing approach is to study perceptions, and then target specific detailed advertising to reinforce positive aspects, and address serious misperceptions to achieve consumer credibility. Most product failures occur despite achieving awareness because credibility (entry into the Consideration set) is never attained.

\section{Availability}

Once the scientific community is aware of exposure science, and some burgeoning scientists are actually considering this career path, the next hurdle is availability. By this, we mean that there have to be programs of study and mentors available in more than just a handful of institutions. If we recall the toxicology example above, almost every major university has some form of program from which prospective students can sample a class or two to see if toxicology suits them; we exposure scientists, do not have this luxury yet. Secondly, we need to encourage and disseminate available opportunities for subsequent employment. Often when a "hiring" organization actually needs someone to serve in an exposure scientist's capacity, they may advertise more broadly because they are not considering exposure scientists as a distinct entity or they believe that there are no trained exposure scientists actually available. As such, awareness of the existence of the field is not enough; we need to work on availability of both training and employment opportunities as well.

\section{MARKETING EXPOSURE SCIENCE}

Based on the above discussions, the first step should be to insert exposure science into the Awareness set of the broad scientific community. This could be accomplished by seeking out scientific venues for writing and lecturing (in journals, at scientific meetings, and at Universities) that are only peripherally related to exposure science, but where the concepts could make a valuable contribution. Although we already do some of this, we need to explicitly and continually identify exposure science as a distinct endeavor. Furthermore, we should invite thought leaders in other disciplines to participate in specific exposure science events (ISES meetings, lectures at EPA, NIOSH, CDC, NAS, invited articles in JESEE, etc.) to create additional awareness on the outside.

Creating exposure science as a viable field of study and employment will require establishing credibility. This is a longer process and should focus primarily on academia. To be considered as a distinct science, we need to provide and foster education and training that differentiates and validates exposure science. Initially, we should encourage or develop some basic classes from our expertise arsenal to be taught at the University level in various Departments of Environmental Study and in Schools of Public Health. We should name classes with titles such as Environmental Exposure Science, Ecologic Exposure Science, Quantitative Exposure Science, Human Biomarkers in Exposure Science, Mathematical Modeling in Exposure Science and so on. Subse- quently, we could encourage/assist certificate programs, minor concentrations, and eventually degrees in Exposure Science.

\section{CHARGE TO THE EXPOSURE SCIENCE COMMUNITY}

The marketing approach for distinguishing Exposure Science as a distinct discipline should be to insert the concepts of exposure research into the overall academic awareness set by introducing it to a wide variety of scientific groups. In parallel, we should focus on a few concentrated efforts at the graduate level and give new students and Professors in environmentally related fields a tangible option to add exposure science to their existing Consideration set that currently contains entries such as Toxicology, Epidemiology, Genomics, and Biostatistics as primary descriptors of their approach to science.

To date, members of the exposure science community have been involved in a variety of outreach efforts beyond our own ISES meetings; we have regularly presented talks at national and international meetings including Society of Toxicology, American Industrial Hygiene Conference \& Exposition, Pittsburgh Conference and Exposition, American Chemical Society, American Society for Mass Spectrometry, International Association of Breath Research, Society of Environmental Toxicology and Analytical Chemistry, Society of Risk Assessment, International Society for Environmental Epidemiology, American Association for Aerosol Research and so on, and have published in numerous journals outside of the specific JESEE umbrella. This is indeed a good start in creating awareness and we should always strive to insert "exposure science" into the searchable keyword lists for our scientific works.

Certain government organizations are already sponsoring events and research that highlight exposure science. Though far too numerous for an inclusive list here, here are some examples: NIEHS has been sponsoring research and hosting meetings under their Exposure Biology program for over 5 years (http://www. niehs.nih.gov/research/supported/programs/exposure/index.cfm); US EPA has the National Exposure Research Laboratory with about 2,000 employees and contractors dedicated to the full spectrum of environmental exposure research (http://www.epa. gov/nerl/), NIOSH has an active program for occupational exposure science, especially in exposure assessment methods, and is currently updating its Occupational Exposure Sampling Strategy Manual (http://www.cdc.gov/niosh/docket/archive/dock et091.html), and CDC operates the National Health and Nutrition Examination Study (NHANES) database that documents a national "snapshot" of biomarkers in human biological media (http:// www.cdc.gov/nchs/nhanes.htm) and the associated National Report on Human Exposure to Environmental Chemicals (http:// www.cdc.gov/exposurereport/).

The National Research Council (NRC) of the National Academy of Sciences (NAS) has also begun to address critical questions about and related to exposure science. An NAS committee is currently developing a long-range vision, conceptual framework, and implementation strategy to advance exposure science. Their report is expected in early 2012. The NAS has also hosted a number of exposure-related symposia under their "Emerging Science for Environmental Health Decisions" program (http:// emergingscience.nas.edu/). Such activities not only bring together practicing exposure scientists, but also develop self-awareness in scientists of related fields that their work actually fits well into this discipline.

For the future, we hope to encourage the ISES membership (and colleagues in related fields) to become emissaries for exposure science and especially to encourage, sponsor, develop, and teach exposure science classes at all University levels. In addition, we should take the opportunity to foster the image of exposure science as a community resource for the broader public, not just for fellow scientists. 
We (the authors) realize that there may be much more activity going on than what is mentioned here, so, with this article, we are also soliciting ideas, successes, and examples of exposure science in academia that we have missed. We hope to write occasional updates to this article that document the great work of ISES in pushing exposure science into the consciousness of the academic sciences community and we encourage the readership to provide the material.

\section{CONFLICT OF INTEREST}

The authors declare no conflict of interest.

\section{ACKNOWLEDGEMENTS}

We thank Prof. John Lynch from the Leeds School of Business, University of Colorado, Boulder, $\mathrm{CO}$, for invaluable discussions regarding marketing approaches and $\mathrm{Dr}$ Keegan Sawyer from the Board on Life Sciences of the National Academy of Sciences, Washington DC, for her insights on academic public health research.

\section{DISCLAIMER}

This commentary represents the opinions of the authors and does not necessarily represent the views of their respective organizations. The report has been reviewed by US EPA, CDC, NIOSH, and NIEHS, and approved for publication.
Joachim D. Pleil ${ }^{1}$, Benjamin C. Blount ${ }^{2}$, Suramya Waidyanatha ${ }^{3}$ and Martin Harper ${ }^{4}$ ${ }^{1}$ Human Exposure and Atmospheric Sciences Division, NERL/ORD, US Environmental Protection Agency (EPA), Research Triangle Park, North Carolina, USA

${ }^{2}$ Division of Laboratory Systems, Centers for Disease Control and Prevention (CDC), Atlanta, Georgia, USA ${ }^{3}$ National Toxicology Program, National Institutes of Environmental Health (NIEHS), Research Triangle Park, North Carolina, USA ${ }^{4}$ Health Effects Laboratory Division, National Institute for Occupational Safety and Health (NIOSH), Morgantown, West Virginia, USA E-mail: pleil.joachim@epa.gov

\section{REFERENCES}

1 Cohen-Hubal E.A., Barr D.B., Koch H.M., and Bahadori T. The promise of exposure science. J Expo Sci Environ Epidemiol 2011: 21(2): 121 - 122

2 Barr D.B. Expanding the role of exposure science in environmental health. J Expo Sci Environ Epidemiol 2006: 16(2): 473.

3 Lioy P.J. Exposure science: a view of the past and milestones for the future. Environ Health Perspect 2010: 118(8): $1081-1090$

4 National Institute for Occupational Safety and Health. Exposure Assessment Methods: Research Needs and Priorities. No. 2002-126, DHSS/NIOSH Publication, Cincinnati, $\mathrm{OH}, 2002$. 